\title{
Short- and long-term subjective medical treatment outcome of trauma surgery patients: the importance of physician empathy
}

This article was published in the following Dove Press journal:

Patient Preference and Adherence

18 September 2014

Number of times this article has been viewed

\author{
Simone Steinhausen' \\ Oliver Ommen² \\ Sunya-Lee Antoine \\ Thorsten Koehler ${ }^{3}$ \\ Holger Pfaff ${ }^{4}$ \\ Edmund Neugebauer \\ 'Institute for Research in Operative \\ Medicine (IFOM), Witten/Herdecke \\ University, Campus Cologne-Merheim, \\ Germany; ${ }^{2}$ Federal Centre for \\ Health Education (BZgA), Cologne, \\ Germany; ${ }^{3}$ Institute for Applied Social \\ Sciences (infas), Bonn, Germany; \\ ${ }^{4}$ Institute for Medical Sociology, \\ Health Services Research and \\ Rehabilitation Science (IMVR), Faculty \\ of Human Science and Faculty of \\ Medicine, University \\ of Cologne, Germany
}

Correspondence: Simone Steinhausen Institute for Research in Operative Medicine Chair of Surgical Research, Faculty of Health - School of Medicine Witten/Herdecke University Ostmerheimer Str 200, Building 38 51109 Cologne, Germany $\mathrm{Tel}+492219895713$

Fax +49 22I 9895730

Email simone.steinhausen@uni-wh.de
Purpose: To investigate accident casualties' long-term subjective evaluation of treatment outcome 6 weeks and 12 months after discharge and its relation to the experienced surgeon's empathy during hospital treatment after trauma in consideration of patient-, injury-, and healthrelated factors. The long-term results are compared to the 6-week follow-up outcomes.

Patients and methods: Two hundred and seventeen surgery patients were surveyed at 6 weeks, and 206 patients at 12 months after discharge from the trauma surgical general ward. The subjective evaluation of medical treatment outcome was measured 6 weeks and 12 months after discharge with the respective scale from the Cologne Patient Questionnaire. Physician Empathy was assessed with the Consultation and Relational Empathy Measure. The correlation between physician empathy and control variables with the subjective evaluation of medical treatment outcome 12 months after discharge was identified by means of logistic regression analysis under control of sociodemographic and injury-related factors.

Results: One hundred and thirty-six patients were included within the logistic regression analysis at the 12-month follow-up. Compared to the 6-week follow-up, the level of subjective evaluation of medical treatment outcome was slightly lower and the association with physician empathy was weaker. Compared to patients who rated the empathy of their surgeon lower than 31 points, patients with ratings of 41 points or higher had a 4.2 -fold higher probability to be in the group with a better medical treatment outcome (3.5 and above) on the Cologne Patient Questionnaire scale 12 months after discharge from hospital $\left(P=0.009, R^{2}=33.5,95 \%\right.$ confidence interval: $1.440-12.629)$.

Conclusion: Physician empathy is the strongest predictor for a higher level of trauma patients' subjective evaluation of treatment outcome 6 weeks and 12 months after discharge from the hospital. Interpersonal factors between surgeons and their patients are possible key levers for improving patient outcomes in an advanced health system. Communication trainings for surgeons might prepare them to react appropriately to their patients' needs and lead to satisfactory outcomes for both parties.

Keywords: long-term outcome, patient-reported outcome, physician-patient interaction, communication, accident, trauma surgery, injury

\section{Introduction}

Longitudinal studies on consequences of injuries and patients' recovery after accidents showed that about $30 \%$ to $80 \%$ of the affected patients found their way back to work or education, according to the time of measurement after the injury. ${ }^{1-4}$ A very small percentage, depending on severity of injury and other aspects, recovered completely 1 year after discharge from the hospital. ${ }^{1,4-7}$ A large number of patients still experience constraints in daily life, ie, $80 \%$ still have functional impairments or mental disorders 
1 year or later after trauma..$^{2,4,8}$ The early onset of medical, nursing, physical, or psychological treatment and emotional support - tailored to the patient's needs - can accelerate the healing process or at least help to reduce negative effects of long-term outcomes. ${ }^{10-13}$ Outcome measurement of medical treatment aspects should be conducted at different levels and dates. ${ }^{14-17}$ To control for possible treatment effects, a time horizon of 1 year is frequently used for checking trauma surgery patients' outcomes in the long run. ${ }^{18}$ Recovery may be measured with variables such as physical- and mental-healthrelated quality of life or return to work after injury. ${ }^{14,15,19-21}$ In addition to the assessment of health-related quality of life, the patient's subjective evaluation of treatment success provides information on how patients perceive the benefits of inpatient care in relation to treatment outcome. ${ }^{22}$ The subjective evaluation of the medical treatment outcome is similar to the concept of "treatment satisfaction" described by Revicki, ${ }^{23}$ as both constructs assess "the level of satisfaction with [...] health status outcomes" and we assume a link with patients' expectations for treatment. ${ }^{23-25}$ The "subjective evaluation of medical treatment outcome" scale (SEMTO) of the Cologne Patient Questionnaire is a brief generic instrument to capture these data and might be sensitive to interpersonal aspects of health care. ${ }^{26-28}$ Interhuman aspects in delivering medical treatment still seem to be underestimated in surgery. ${ }^{29}$ Dealing with matters of life and death and encountering severely injured patients are daily routine for trauma surgeons, but for the patient it is an exceptional situation. ${ }^{29,30}$ Physical or mental impairments after an accident often do not improve despite the best possible treatment even over a long period. Therefore, substantial increases in the measured quality of life can not always be expected. Patients need to be carefully prepared for their altered circumstances, ie, helped to adjust their expectations towards a more realistic notion of their treatment outcome..$^{24,31}$ The authors have published the shortterm results on the subjective evaluation of treatment outcome (6 weeks after discharge) regarding the correlation with physician empathy, showing that the latter was connected with a higher probability for better subjective treatment outcomes. ${ }^{28}$ It is desirable that positive effects of treatment should be robust over a longer period. Therefore, in the present analysis, the temporal changes in patient-reported outcomes are investigated with a focus on the correlation of physician empathy with the long-term subjective evaluation of treatment outcome. The authors defined physician empathy as follows:

Physician's ability “to understand the patient's situation, perspective and feelings, to communicate that understanding and check its accuracy, and to act on that understanding with the patient in a helpful (therapeutic) way" as well as the physician's sensitivity to patient concerns $[\ldots] \cdot{ }^{28,32}$

Based on the results of the short-term patient outcomes, the authors assume that the long-term subjective evaluation of the medical treatment outcome will correlate with the patient perceived quality of the patient-physician interaction. Janssen et al found that patients' trust in physicians was associated positively with a higher evaluation of the subjective treatment outcome. ${ }^{22}$ Adverse events occurring after receiving a dental implant were associated with worse patient-reported medical treatment outcomes. ${ }^{33}$ The authors found that the subjective evaluation of medical treatment outcome 6 weeks after discharge correlates positively with living with a partner and negatively with having a mental disorder during hospitalization. ${ }^{28}$ Though the subjective evaluation of medical treatment outcome by trauma patients might be influenced by further treatment and disease-specific or biopsychosocial factors, no published evidence was found on additional influencing factors. ${ }^{22}$ The objective of this analysis is to investigate accident casualties' long-term subjective evaluation of treatment outcome 6 weeks and 12 months after discharge and its relation to the experienced surgeon's empathy during hospital treatment after trauma in consideration of patient-, injury-, and health-related factors.

\section{Materials and methods \\ Study design, population, and ethics}

Data for this analysis were collected within a pre-postdesign study on the effects of communication training for trauma surgeons, named "Advanced Trauma Psychosocial Support - ATPS", funded by the German Research Foundation (Deutsche Forschungsgemeinschaft [DFG] grant number PF 407/2-1). Patients hospitalized between May 2008 and April 2011 at a German trauma-surgical ward of a level one trauma center were included in the study. Inclusion and exclusion criteria were described previously. ${ }^{28}$ The study was approved by the Medical Ethics Committee of Witten/ Herdecke University on April 8, 2008, number 14/2007.

\section{Sample and procedure}

A total of 3,299 patients admitted to the trauma center were screened for study inclusion. Three thousand and fifty-six patients did not meet the inclusion criteria or refused to participate. The flow chart in Figure 1 shows the inclusion and exclusion flows of patients as well as the study participation. Data from patients were collected using three different questionnaires: 243 patients between the ages of 18 and 


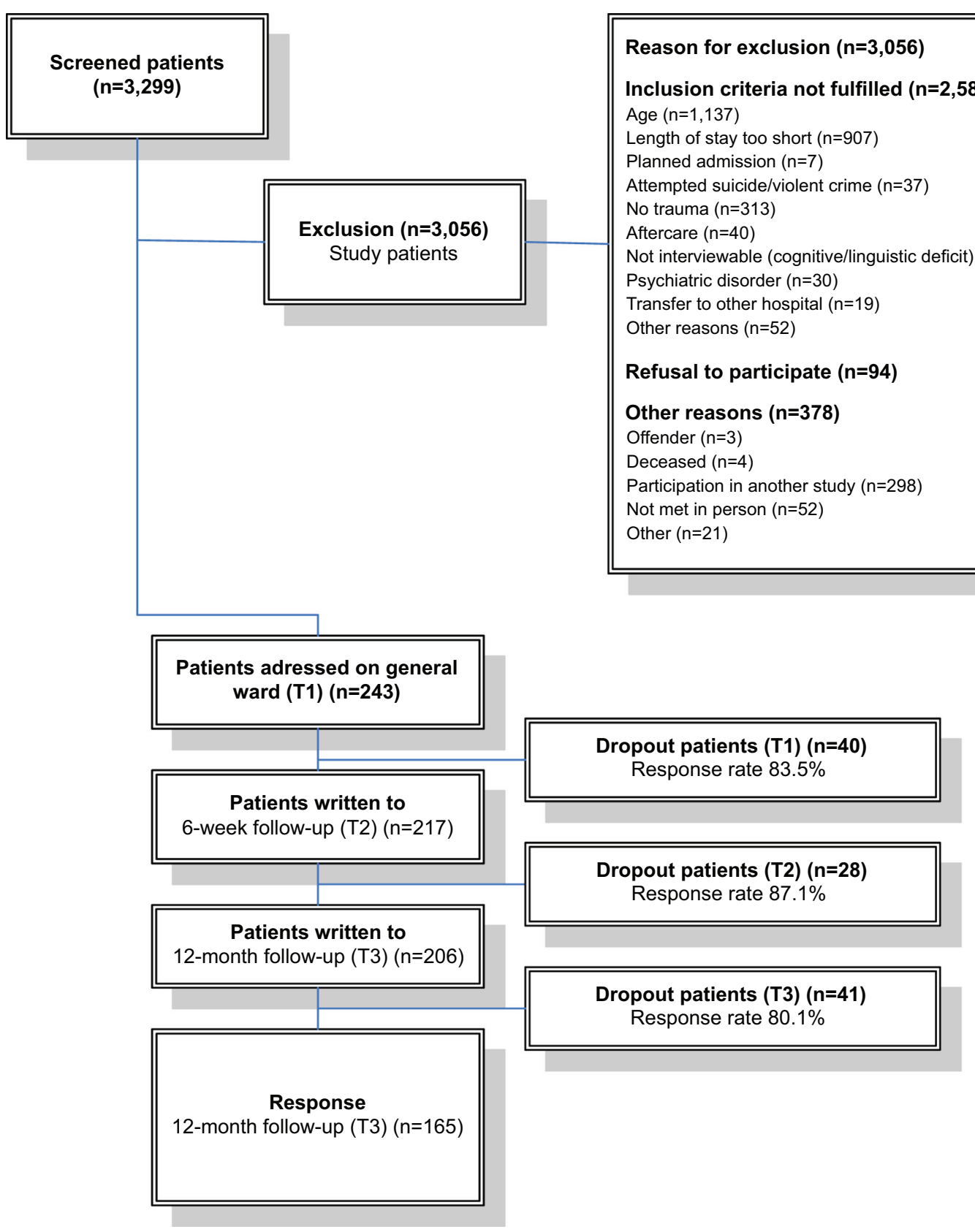

Figure I Flowchart of study participants.

70 remained and received the first questionnaire at the surgical ward with questions regarding social demographics and psychological assessment during hospitalization. ${ }^{34}$ Two hundred and three of them returned a completed questionnaire. Six weeks after discharge, 217 patients received a questionnaire by post (6-week follow-up questionnaire) including questions about physician empathy, the subjective evaluation of treatment outcome, and health-related quality of life. One hundred and eighty-nine patients completed the 6-week follow-up questionnaire (Figure 1). One year after discharge, a written questionnaire with questions on the subjective evaluation of medical treatment outcome, health-related quality of life, anxiety, and depression was sent to 206 patients, of which 165 patients returned it completed. The survey was designed according to the Dillman's Total Design Method. ${ }^{35}$ Questionnaires are available from the authors upon request.

\section{Measures}

\section{Evaluation of medical treatment outcome}

The SEMTO was measured 6 weeks and 12 months after discharge from the hospital with a module from the Cologne Patient Questionnaire (CPQ; Kölner Patientenfragebogen, 
KPF) and represents an outcome measure of patients' subjective impression of the treatment and its results. ${ }^{26}$ The CPQ was validated in several research projects. ${ }^{36-39}$ The four items of the SEMTO index are: (1) I was very satisfied with my medical treatment. (2) I believe that the treatment provided is effective. (3) The treatment makes me feel better. (4) The treatment has improved my quality of life. Patients were asked to express their approval on a four-point Likert scale from "do not agree at all" (=1), "rather disagree" $(=2)$, "rather agree" $(=3)$, to "completely agree" (=4). Valuations were added up and divided by the number of answered items to form the variable SEMTO. Possible ratings had scores between 1 and 4; higher values represented a higher evaluation of SEMTO. Since the frequency analyses and Kolmogorov-Smirnov tests (not presented) of SEMTO 6 weeks and 12 months after discharge showed a right-skewed non-normal distribution, the scales were divided into dichotomized variables by a split at 3.5 points. Patients were split into two subgroups: "high" (=3.5 to 4 points) versus "low" (=1 to $<3.5$ points) according to their score on the SEMTO.

\section{Physician empathy}

Physician empathy was assessed with the German version of the Consultation and Relational Empathy (CARE) Measure. ${ }^{40,41}$ The one-dimensional CARE Measure comprises 10 items related to patients' perception of physicians' understanding of and response to their concerns and fears. ${ }^{42}$ The items of the CARE Measure in our questionnaire were introduced with the sentence: "How did your attending physicians behave?" Patients can indicate their agreement to 10 statements on a five-point scale from 1 ("Does not apply at all") to 5 ("Fully applies"); eg, "Did the physician behave in a manner that made you feel completely at ease?" The entire questionnaire can be obtained from the authors. The psychometric properties of the German version of the CARE Measure are very satisfactory and have already been reported. ${ }^{40}$ The ratings of all items were added up so the possible score had values between 10 and 50. Mercer et al depicted differences by "high", "average," and "low" as well as by "above average", "average," and "below average" physician empathy depending on study-based results. ${ }^{43,44}$ In the present analysis, the score of the CARE Measure was also divided into three groups for a better interpretation of the results, but the authors chose cutoffs based on theoretical considerations. According to the German version of the CARE Measure, an approach based on its response categories was chosen; with respect to a sufficient group size in each category. In the German version of the CARE Measure, the response categories are "fully applies", "largely applies", "partially applies", "does rather not apply", and "does not apply at all". ${ }^{45}$ Values in the range of 41 to 50 suggest that the majority of questions were answered with "largely applies" (=4) and at least one "fully applies" (=5). This might be considered as perceiving "high" physician empathy, also because this range of values is higher than the mean and median values. Values between 31 to 40 points can be achieved if most of the items are rated with the categories "partially applies" (=3) or "largely applies" (=4) or if the lowest ratings are equalized by the highest ratings. This value range was defined as "middle" physician empathy. The mean (38.26) and median (40) fall within this category. Values of 30 and lower were considered as "low" empathy as ratings have to range between "partially applies" (=3), "does rather not apply" (=2), and "does not apply at all" (=1) or the highest ratings were set off by the lowest ratings. The coefficient of covariation was computed for each case and it ranged from zero to 0.71 . That means that in no case was the standard deviation (SD) higher than the mean value. There was a strong tendency within the present study population to rate the ten items of the CARE Measure with similar values on an individual level. Thus "physician empathy" was divided into three groups: "low" for empathy scores from 10 to 30 points, "middle" for empathy scores from 31 to 40 points, and "high" for empathy scores from 41 to 50 points.

\section{Health-related quality of life and psychosocial care}

Health-related quality of life at 6 weeks and 12 months after discharge was measured using the 36-Item Short Form Survey Instrument (SF-36). ${ }^{46}$ The physical- and mentalhealth-related quality of life summary scores were computed according to Bullinger et al. ${ }^{46}$ Psychosocial care by physicians was measured with the respective CPQ subscale. ${ }^{47}$

\section{Sociodemographics and disease characteristics}

Sociodemographics were taken from the first questionnaire on general wards. Length of stay, injury severity, and existence of an extremity injury were derived from medical records. Education was operationalized as having a "high school graduation", coded with " 1 " if the patient had a high school education or with " 0 " if not. Length of stay represents the number of days in hospital from admission to discharge. Injury severity was determined by the Injury Severity Score (ISS) within a range from 1 to $75 .^{48}$ The variable "extremity injury" was divided into three groups: "no", "Abbreviated Injury Scale (AIS) $\leq 2$ ", and "AIS $\geq 3$ ". Mental disorders at the time of hospitalization were measured with the German version of the Hospital Anxiety and Depression Scale (HADS-D) and the Impact of Event 
Table I Evaluation plan

\begin{tabular}{llll}
\hline Characteristics & $\begin{array}{l}\text { On general } \\
\text { wards }\end{array}$ & $\begin{array}{l}\text { 6 weeks after } \\
\text { discharge }\end{array}$ & $\begin{array}{l}\text { I2 months after } \\
\text { discharge }\end{array}$ \\
\hline $\begin{array}{l}\text { Sociodemographics } \\
\text { ISS }\end{array}$ & $\times$ & $\times$ \\
Extremity injury & & $\times$ \\
Length of stay & $\times$ & $\times$ \\
Posttraumatic stress (IES-R) & $\times$ & & $\times$ \\
Anxiety (HADS-D) & $\times$ & $\times$ & $\times$ \\
Depression (HADS-D) & & & \\
Empathy (CARE measure) & & \\
Patient satisfaction: & & $\times$ & $\times$ \\
$\quad$ CPQ-PSC & & $\times$ & $\times$ \\
CPQ-SEMTO & & $\times$ & \\
Quality of life (SF-36) & & & \\
\hline
\end{tabular}

Abbreviations: CARE, Consultation and Relational Empathy; CPQ, Cologne Patient Questionnaire; HADS-D, German Hospital Anxiety and Depression Scale; IES-R, Impact of Event Scale - Revised; ISS, Injury Severity Score; PSC, psychosocial care; SEMTO, subjective evaluation of medical treatment outcome; SF-36, 36-Item Short Form Survey Instrument.

Scale (IES-R). ${ }^{49-51}$ HADS-D was also used within the 12-month follow-up. Table 1 shows an overview of evaluation time and measures.

\section{Statistical analysis}

Statistical analyses were carried out with the statistical package SPSS (Version 21; IBM Corporation, Armonk, NY, USA). Only a small amount of patients showed symptoms on the HADS-D and IES-R scales during hospitalization. Therefore a new variable, "mental disorder", was computed with the value " 0 " for the absence of symptoms and "1" meaning that the patients had at least one symptom on one or both scales. Descriptive analyses were conducted to present means and frequency distributions of relevant variables (Tables 2 and 3). Changes over time in SEMTO and SF-36 Summary Scores were computed (Table 3). Chi-square, Mann-Whitney $U$-tests, and two-sided $t$-tests for independent samples were performed to check for statistically significant differences between the dichotomous, categorical, and metric variables for the high and the low SEMTO groups for the 6-week and the 12-month follow-up (Tables 4 and 5). Spearman or Pearson correlation analyses were conducted to identify possible associations among the relevant variables. Analyses of variance were executed to check for group differences between the "low", "middle", and "high" physician empathy groups. The correlation of physician empathy with SEMTO 6 weeks and 12 months after discharge was determined with a logistic regression under control for relevant sociodemographic and healthrelated variables (Tables 6 and 7). Regression analyses were conducted for both the SEMTO 6 weeks and 12 month after discharge to investigate if the correlations found for physician empathy and SEMTO 6 weeks after discharge were replicable and valid 1 year after discharge. The variables age, sex, high school graduation, living with a partner, length of stay in hospital, and injury severity were included in the first block (Model 1A, Table 6 and Model 1B, Table 7). For the 6-week follow-up data, the variable "mental disorder at hospitalization" was included within the basic logistic regression, as significantly more patients with a mental disorder at hospitalization were identified within the lower SEMTO group at the 6-week follow-up. The threegroup variable "physician empathy" was added in the final block (Model 2A, Table 6 and Model 3B, Table 7). The SF-36 Mental and Physical Summary Scores 6 weeks after discharge were introduced in Model 2B (Table 7). Since the SEMTO scale contains a question on health-related quality of life and since health-related quality was also measured with the SF-36 at the same time, a conceptual overlap with the SF-36 Summary Scores might lead to a bias. Thus, the authors decided to omit the SF-36 Summary Scores of the 6-week follow-up in the logistic regression analysis for the short-term outcome. Due to the assumed overlap, the SF-36 summary scores 12 months after discharge were not included in the regression models for the long-term subjective evaluation of the medical treatment outcome, although mean differences for the high and low SEMTO groups were identified. On the other hand, the health-related quality of life measured 6 weeks after discharge and referring to the "last 4 weeks" was added as a predictor for the SEMTO 12 months after discharge. As the survey time points were different, the short-term health-related quality of life should not skew the validity of the analysis. The SF-36 Physical Summary Score 6 weeks after discharge had significant mean differences from the long-term SEMTO group in the bivariate analysis (Table 5). 
Regression analyses included 169 patients for SEMTO 6 weeks after discharge and 136 patients for SEMTO 12 months after discharge. Patients with incomplete data on partnership and high school graduation were included in all regressions by introducing a category "unknown" for the missing values, as valid estimations were not possible. This approach applied to 13 and seven patients with no details on high school graduation and for nine and four patients with no details on life partnership for the regression analyses on the SEMTO 6 weeks and 12 months after discharge, respectively. In the 12-months follow-up, no significant group differences in frequency distribution were identified for mental disorders at time of hospitalization or at 12 months after discharge (Table 5). So the authors decided to exclude this variable from the logistic regression analysis.

\section{Results}

\section{Sociodemographic and injury-related characteristics}

Patient characteristics and injury-related variables are displayed in Table 2. Age ranged from 18 to 70 years with a mean of 45.8 years (SD 14.6 years). One hundred and twenty-six (58.1\%) out of 217 respondents were male and $91(41.9 \%)$ were female. One-quarter of the respondents had a high school graduation $(n=57,26.3 \%)$; over $60 \%$ of the patients were not high school graduates $(n=138)$; and 22 patients did not specify their level of education. One hundred and thirty-five (62.2\%) respondents were living together with a partner, $63(29.0 \%)$ were not, and 19 patients $(8.8 \%)$ did not specify. The default minimum length of stay in hospital was 5 days, the longest stay amounted to 95 days. Seventeen of the included patients stayed only 3 or 4 days but were not excluded from the analyses (intention-to-treat). The patients showed ISS values from 1 to 48 , with a mean of 6.35 (SD 5.5). Forty-nine (24.3\%) patients had no extremity injury, about $75 \%$ had extremity injuries with an AIS up to $2(59.9 \%, \mathrm{n}=121)$ or from 3 to $4(15.8 \%, \mathrm{n}=32)$. Thirty-nine (19.9\%) of 196 respondents had at least one mental disorder diagnosed at time of hospitalization with the HADS-D or IES-R (anxiety, depression, or posttraumatic stress). Twelve months after discharge, 25 (17.9\%) of 140 patients had at least one symptom on the HADS-D scale. IES-R was not assessed. We found significant differences in mean age ( $P=0.021$ and $P=0.002)$ and in the frequency distribution of sex $(P=0.001$ and $P=0.005)$ between study participants and dropout patients for the 6-week follow-up and the 12-month follow-up, respectively (Table 8).
Table 2 Patient and health-related characteristics

\begin{tabular}{|c|c|c|c|}
\hline & $\mathbf{N}$ & $\%$ & \\
\hline Sex & 217 & & \\
\hline Male & 126 & 58.1 & \\
\hline Female & 91 & 41.9 & \\
\hline High School & 217 & & \\
\hline Yes & 57 & 26.3 & \\
\hline No & 138 & 63.6 & \\
\hline Unknown & 22 & 10.1 & \\
\hline Living with partner & 217 & & \\
\hline Yes & 135 & 62.2 & \\
\hline No & 63 & 29.0 & \\
\hline Unknown & 19 & 8.8 & \\
\hline Extremity injury & 202 & & \\
\hline None & 49 & 24.3 & \\
\hline Up to AIS 2 & 121 & 59.9 & \\
\hline AIS 3 to 4 & 32 & 15.8 & \\
\hline Anxiety ${ }^{a}$ & 194 & & \\
\hline Yes & 31 & 16.0 & \\
\hline No & 91 & 84.0 & \\
\hline Depression $^{\mathrm{a}}$ & 195 & & \\
\hline Yes & 12 & 11.3 & \\
\hline No & 96 & 88.7 & \\
\hline Posttraumatic & 194 & & \\
\hline \multicolumn{4}{|l|}{ stress $^{\mathrm{a}}$} \\
\hline Yes & 14 & 7.2 & \\
\hline No & 180 & 92.8 & \\
\hline Mental disorder & 196 & & \\
\hline Yes & 39 & 19.9 & \\
\hline No & 157 & 80.1 & \\
\hline Anxiety ${ }^{b}$ & 140 & & \\
\hline Yes & 20 & 14.3 & \\
\hline No & 120 & 85.7 & \\
\hline Depression $^{\mathrm{b}}$ & 140 & & \\
\hline Yes & 14 & 10.0 & \\
\hline No & 126 & 90.0 & \\
\hline Mental disorder ${ }^{b}$ & 140 & & \\
\hline Yes & 25 & 17.9 & \\
\hline \multirow[t]{2}{*}{ No } & 115 & 88.1 & \\
\hline & Mean & SD & Range [possible] \\
\hline Age (years) & $45.8(\mathrm{~N}=217)$ & 14.6 & I8-70 [ $18-70]$ \\
\hline Length of stay (days) & $13.1(\mathrm{~N}=216)$ & 13.2 & $3-5[5-\infty]$ \\
\hline ISS & $6.35(\mathrm{~N}=202)$ & 5.5 & $\mathrm{I}-48[\mathrm{I}-75]$ \\
\hline
\end{tabular}

Notes: aAt hospitalization. ${ }^{\mathrm{b}} \mathrm{At}$ I2-month follow-up.

Abbreviations: AIS, Abbreviated Injury Scale; ISS, Injury Severity Score; SD, standard deviation.

\section{Patient-reported outcomes measures}

The descriptive statistics for the SEMTO 6 weeks and 12 months after discharge, physician empathy, and SF-36 Summary Scores are displayed in Table 3. One-fifth of patients rated physician empathy not higher than 30 points. From the 6-week to the 12-month follow-up, SEMTO ratings fell on average by -0.102 (SD 0.66) points, and healthrelated quality of life increased on average by 9.15 (SD 9.01) points on the Physical Summary and by 5.32 points on the 
Table 3 Descriptive statistics for patient evaluations and outcome measures

\begin{tabular}{|c|c|c|c|c|}
\hline Characteristics & $\mathbf{N}$ & $\%$ & & \\
\hline SEMTO6W dichotomized* & 183 & & & \\
\hline High (3.5+) & 101 & 55.2 & & \\
\hline Low $(<3.5)$ & 82 & 44.89 & & \\
\hline SEMTOI2M dichotomized** & 158 & & & \\
\hline High $(3.5+)$ & 78 & 49.4 & & \\
\hline Low $(<3.5)$ & 80 & 50.6 & & \\
\hline Empathy 3 groups & 183 & & & \\
\hline Low $(10-30)$ & 38 & 20.8 & & \\
\hline Middle $(3 \mid-40)$ & 56 & 30.6 & & \\
\hline \multirow[t]{2}{*}{ High (4I-50) } & 89 & 48.6 & & \\
\hline & Mean & SD & Median & Range [theoretical] \\
\hline SEMTO6W scale & 3.37 & 0.61 & 3.5 & $1.5-4.0[1-4]$ \\
\hline SEMTOI2M scale & 3.22 & 0.73 & 3.25 & $1-4[1-4]$ \\
\hline$\Delta$ SEMTO & -0.102 & 0.66 & 0 & -2.0 to $2.0[-4$ to 4$]$ \\
\hline Empathy scale & 38.26 & 9.19 & 40 & $12-50[10-50]$ \\
\hline CPQ Scale PSC & 3.03 & 0.66 & 3.09 & $1-4[1-4]$ \\
\hline 6 W SF-36 PSS & 35.93 & 7.47 & 35.08 & $14-59[0-100]$ \\
\hline 12 M SF-36 PSS & 44.76 & 9.35 & 46.67 & $18.9-62[0-100]$ \\
\hline 6 W SF-36 MSS & 43.72 & 13.03 & 45.91 & $16.8-70.2[0-100]$ \\
\hline 12 M SF-36 MSS & 48.45 & 12.38 & 52.93 & $12.4-67.2[0-100]$ \\
\hline$\Delta$ SF-36 PSS & 9.15 & 9.01 & 7.67 & -11.1 to $37.3[-100$ to 100$]$ \\
\hline$\Delta$ SF-36 MSS & 5.32 & 12.00 & 5.32 & -28.9 to $38.1[-100$ to 100$]$ \\
\hline
\end{tabular}

Notes: *SEMTO6W split at a value of 3.5 points. **SEMTOI2M split at a value of 3.5 points.

Abbreviations: 6 W SF-36, 6-week 36-Item Short Form Survey Instrument; 12 M SF-36, 12-month 36-Item Short Form Survey Instrument; CPQ, Cologne Patient Questionnaire; MSS, Mental Summary Score; PSC, psychosocial care; PSS, Physical Summary Score; SD, standard deviation; SEMTO, subjective evaluation of medical treatment outcome; SEMTO6W, subjective evaluation of medical treatment outcome 6 weeks after discharge; SEMTOI2M, subjective evaluation of medical treatment outcome 12 months after discharge; $\Delta$, change from 6 weeks to 12 months measurement.

Mental Summary Score. The mean values for SEMTO differed significantly between the 6-week follow-up and the 12-month follow-up ( $P=0.066)$, as a paired samples $t$-test showed.

\section{Bivariate analyses of the main outcome}

In a Spearman correlation analysis (not presented), SEMTO 6 weeks after discharge correlated with the SF-36 Mental Summary Score at 6 weeks after discharge $(0.203, P=0.007)$, physician empathy $(0.559, P<0.001)$, and SEMTO 12 months after discharge $(0.494, P<0.001)$. SEMTO 12 weeks after discharge correlated with the SF-36 Physical Summary Score at 6 weeks after discharge $(0.223, P=0.008)$, physician empathy $(0.453, P<0.001)$, SF-36 Physical and Mental Summary Scores at 12 months after discharge (0.283, $P<0.001$ and $0.225, P=0.005$, respectively), and SEMTO 6 weeks after discharge $(0.494, P<0.001)$. Physician empathy correlated (Pearson) with the SF-36 Mental Summary scores at 6 weeks $(0.160, P=0.033)$ and 12 months after discharge $(0.242, P=0.004)$. The higher and the lower SEMTO groups 6 weeks after discharge showed significant differences in the following aspects (Table 4): the average age of 49 years in the higher SEMTO group was significantly higher than in the lower group (44.2 years,
$P=0.023$ ); a higher percentage of patients with a high SEMTO at 6 weeks after discharge lived with a partner ( $75.2 \%$ versus $52.4 \%$ ); and the mean empathy of the higher SEMTO group of 42.3 was significantly higher than the lower SEMTO group (33.3, $P<0.001)$. The medium rankings of the CPQ-Scale Psychosocial Care by Physicians and the SEMTO 12 months after discharge indicated significantly higher values for the higher SEMTO group $(P<0.001)$. The SF-36 Mental Summary Score 6 weeks after discharge was significantly higher in the high SEMTO group (45.64) than in the low SEMTO group (41.39, $P=0.029)$. Significantly more patients in the high SEMTO group had no diagnosis of a mental disorder on the HADS-D and IES-R scales during hospitalization ( $86.9 \%$ versus $73 \%$ ) and 12 months after discharge $(90 \%$ versus $74.1 \%, P=0.018)$ than in the low SEMTO group. Group differences for high and low SEMTO at 12 months after discharge are presented in Table 5 . In the high SEMTO group, significantly more patients lived with a partner $(75.6 \%$ versus $58.8 \%, P=0.055)$. The medium ranking for the ISS suggested a higher injury severity in the high SEMTO group $(P=0.031)$. The mean physician empathy rating was significantly higher in the high SEMTO group (40.9) than in the low SEMTO group $(35.5, P<0.001)$. Psychosocial care and SEMTO 6 weeks 
Table 4 Patients with high versus patients with low SEMTO6W: means (two-sided t-test for independent samples), medium ranking (Mann-Whitney $U$-test), percentages (chi-square test), and $P$-values

\begin{tabular}{|c|c|c|c|}
\hline Characteristics & High SEMTO (n=I0I) (\%) & Low SEMTO (n=82) (\%) & $P$-value \\
\hline Age ${ }^{a}$, years & 49.04 & 44.19 & 0.023 \\
\hline \multicolumn{4}{|l|}{ Sex } \\
\hline Female $(\mathrm{n}=87)$ & $47(46.5)$ & $40(48.8)$ & \multirow[t]{2}{*}{0.762} \\
\hline Male $(n=96)$ & $54(53.5)$ & $42(5 \mid .2)$ & \\
\hline \multicolumn{4}{|l|}{ Partner $^{c}$} \\
\hline Yes $(n=119)$ & $76(75.2)$ & $43(52.4)$ & \multirow[t]{3}{*}{0.006} \\
\hline No $(n=5 I)$ & $20(19.8)$ & $31(37.8)$ & \\
\hline Unknown $(n=13)$ & $5(5.0)$ & $8(9.8)$ & \\
\hline \multicolumn{4}{|l|}{ High school ${ }^{c}$} \\
\hline Yes (n=49) & $25(32.1)$ & $24(30.0)$ & \multirow[t]{3}{*}{0.181} \\
\hline No $(n=100)$ & $46(59.0)$ & $54(67.5)$ & \\
\hline Unknown (n=9) & $7(9.0)$ & $2(2.5)$ & \\
\hline $\mathrm{ISS}^{2}$ & 89.1 & 84.3 & 0.495 \\
\hline Length of stay ${ }^{b}$ & 94.8 & 88.5 & 0.425 \\
\hline \multicolumn{4}{|l|}{ Extremity injuryc } \\
\hline No $(n=39)$ & $20(20.6)$ & $19(25.0)$ & \multirow[t]{3}{*}{0.568} \\
\hline AIS $\leq 2(n=I I 0)$ & $65(67.0)$ & $45(59.2)$ & \\
\hline AIS $\geq 3 \quad(n=24)$ & $12(12.4)$ & $12(15.8)$ & \\
\hline Empathy & 42.29 & 33.30 & $<0.001$ \\
\hline CPQ-PSC ${ }^{b}$ & 115.1 & 63.5 & $<0.001$ \\
\hline SEMTOI2M & 89.53 & 52.4 & $<0.001$ \\
\hline $6 \mathrm{~W} \mathrm{SF-36} \mathrm{PSS}{ }^{a}$ & 36.10 & 35.74 & 0.750 \\
\hline 6 W SF-36 MSS & 45.64 & 41.39 & 0.029 \\
\hline 12 M SF-36 PSC & 45.87 & 43.91 & 0.202 \\
\hline 12 M SF-36 MSCa & 49.69 & 47.40 & 0.270 \\
\hline \multicolumn{4}{|c|}{ Mental disorder in hospital ${ }^{c, d}$} \\
\hline Yes $(n=33)$ & $13(13.7)$ & $20(27.0)$ & \multirow[t]{2}{*}{0.021} \\
\hline No $(n=140)$ & $86(86.9)$ & $54(73.0)$ & \\
\hline \multicolumn{4}{|c|}{ Mental disorder at 12 months $^{\mathrm{c}, \mathrm{e}}$} \\
\hline Yes $(n=22)$ & $7(10.0)$ & $15(25.9)$ & \multirow[t]{2}{*}{0.018} \\
\hline No $(n=106)$ & $63(90.0)$ & $43(74.1)$ & \\
\hline
\end{tabular}

Notes: ${ }^{a}$ Independent samples $t$-test. ${ }^{b}$ Mann-Whitney U-Test. ${ }^{c}$ Chi-square test. dMeasured with German Hospital Anxiety and Depression Scale and Impact of Event-Scale Revised at hospitalization. eMeasured with German Hospital Anxiety and Depression Scale 12 months after discharge.

Abbreviations: 6 W SF-36, 6-week 36-Item Short Form Survey Instrument; 12 M SF-36, I2-month 36-Item Short Form Survey Instrument; CPQ, Cologne Patient Questionnaire; ISS, Injury Severity Score; MSS, Mental Summary Score; PSC, psychosocial care; PSS, Physical Summary Score; SEMTO, subjective evaluation of medical treatment outcome; SEMTO6W, subjective evaluation of medical treatment outcome 6 weeks after discharge; SEMTOI2M, subjective evaluation of medical treatment outcome 12 months after discharge.

after discharge had higher medium rankings in the high SEMTO group $(P<0.001)$. The high SEMTO group had a higher mean value on the SF-36 Physical Summary Scores 6 weeks and 12 months after discharge (0.009 and 0.005 , respectively). The SEMTO mean differences for the three empathy groups were significant (Table 9) and showed rising gradients according to the physician empathy level. Mental disorders diagnosed during hospitalization were equally distributed over the high and low SEMTO group. Twelve months after discharge, more patients without anxiety or depression were in the high SEMTO group compared to the low SEMTO group, but this difference was not significant (87.1\% versus $75.8 \% ; P=0.087$ ).

\section{Logistic regression on subjective evaluation of medical treatment outcome 6 weeks and 12 months after discharge}

The basic logistic regression model (Model 1A, Table 6) was calculated for SEMTO 6 weeks after discharge with the control variables age, sex, high school education, living with a partner, length of stay in hospital, ISS, and having at least one mental disorder at hospitalization (Nagelkerke's $R^{2}=16.0 \%$ ). Study patients who lived with their partner had a significant 2.4-fold increased chance to be in the high SEMTO group 6 weeks after discharge ( $P=0.023,95 \%$ confidence interval [CI]: 1.126-5.098). Age, sex, high school education, length of stay in hospital, ISS, 
Table 5 Patients with high versus patients with low SEMTOI2M: means (two-sided $t$-test for independent samples), medium ranking (Mann-Whitney $U$-test), percentages (chi-square test), and $P$-values

\begin{tabular}{|c|c|c|c|}
\hline Characteristics & High SEMTO (n=78) (\%) & Low SEMTO $(n=80)(\%)$ & $P$-value \\
\hline Age $e^{a}$ years & 47.76 & 46.46 & 0.573 \\
\hline \multicolumn{4}{|l|}{ Sex } \\
\hline Female $(\mathrm{n}=74)$ & $35(44.9)$ & $39(48.8)$ & \multirow[t]{2}{*}{0.625} \\
\hline Male $(\mathrm{n}=84)$ & $43(55.1)$ & $4 \mid(5 \mid .3)$ & \\
\hline \multicolumn{4}{|l|}{ Partner } \\
\hline Yes $(n=106)$ & $59(75.6)$ & $47(58.8)$ & \multirow[t]{3}{*}{0.055} \\
\hline No $(n=44)$ & $15(19.2)$ & $29(36.3)$ & \\
\hline Unknown $(n=8)$ & $4(5.1)$ & $4(5.0)$ & \\
\hline \multicolumn{4}{|l|}{ High schoolc } \\
\hline Yes $(n=49)$ & $25(32.1)$ & $24(30.0)$ & \multirow[t]{3}{*}{0.181} \\
\hline No $(n=100)$ & $46(59.0)$ & $54(67.5)$ & \\
\hline Unknown $(\mathrm{n}=9)$ & $7(9.0)$ & $2(2.5)$ & \\
\hline $\mathrm{ISS}^{\mathrm{b}}$ & 81.4 & 67.6 & 0.031 \\
\hline Length of stay ${ }^{b}$ & 80.0 & 79.1 & 0.900 \\
\hline \multicolumn{4}{|l|}{ Extremity injury ${ }^{c}$} \\
\hline No $(n=35)$ & $16(21.6)$ & $19(25.7)$ & \multirow[t]{3}{*}{0.799} \\
\hline AIS $\leq 2(n=91)$ & $46(62.2)$ & $45(60.8)$ & \\
\hline AIS $\geq 3(n=22)$ & $12(16.2)$ & $10(13.5)$ & \\
\hline Empathy & 40.9 & 35.5 & $<0.001$ \\
\hline $\mathrm{PSC}^{\mathrm{b}}$ & 88.9 & 57.0 & $<0.001$ \\
\hline SEMTO6W $W^{b}$ & 88.2 & 57.7 & $<0.001$ \\
\hline 6 W SF-36 PSS & 37.39 & 34.31 & 0.009 \\
\hline 6 W SF-36 MSS & 44.59 & 42.42 & 0.316 \\
\hline 12 M SF-36 PSCa & 46.85 & 42.7 & 0.005 \\
\hline 12 M SF-36 MSCa & 50.21 & 46.71 & 0.077 \\
\hline \multicolumn{4}{|c|}{ Mental disorder in hospital ${ }^{c, d}$} \\
\hline Yes $(n=29)$ & I3 (I7.3) & $16(20.8)$ & \multirow[t]{2}{*}{0.589} \\
\hline No $(n=123)$ & $62(82.7)$ & $61(79.2)$ & \\
\hline \multicolumn{4}{|c|}{ Mental disorder at 12 months ${ }^{c, e}$} \\
\hline Yes $(n=25)$ & $9(12.9)$ & $16(24.2)$ & \multirow[t]{2}{*}{0.087} \\
\hline No $(n=|I|)$ & $61(87.1)$ & $50(75.8)$ & \\
\hline
\end{tabular}

Notes: alndependent samples $t$-test. ${ }^{D}$ Mann-Whitney U-test. ${ }^{~ C}$ Chi-square test. ${ }^{d}$ Measured with German Hospital Anxiety and Depression Scale and Impact of Event-Scale Revised at hospitalization. eMeasured with German Hospital Anxiety and Depression Scale 12 months after discharge.

Abbreviations: 6 W SF-36, 6-week 36-Item Short Form Survey Instrument; 12 M SF-36, 12-month 36-Item Short Form Survey Instrument; CPQ, Cologne Patient Questionnaire; ISS, Injury Severity Score; MSS, Mental Summary Score; PSC, psychosocial care; PSS, Physical Summary Score; SEMTO, subjective evaluation of medical treatment outcome; SEMTO6W, subjective evaluation of medical treatment outcome 6 weeks after discharge; SEMTOI2M, subjective evaluation of medical treatment outcome 12 months after discharge.

Table 6 Results of logistic regression models with the dichotomized variable SEMTO6W after discharge as the dependent variable

\begin{tabular}{lll}
\hline $\begin{array}{l}\text { Dependent variable: SEMTO6W } \\
\text { dichotomized }\end{array}$ & $\begin{array}{l}\text { Model IA odds ratios } \\
(\boldsymbol{P} \text {-values) } \mathbf{N}=\mathbf{I 6 9}\end{array}$ & $\begin{array}{l}\text { Model 2A odds ratios } \\
(\boldsymbol{P} \text {-values) } \mathbf{N}=\mathbf{I 6 9}\end{array}$ \\
\hline Age (per year) & $1.022(0.092)$ & $1.017(0.239)$ \\
Sex (female) & $0.805(0.545)$ & $1.337(0.486)$ \\
High school (yes) & $1.124(0.758)$ & $1.188(0.686)$ \\
Partner (yes) & $2.396(0.023)$ & $3.176(0.010)$ \\
Length of stay in hospital (days) & $1.010(0.525)$ & $1.018(0.300)$ \\
ISS (per point on scale) & $1.013(0.721)$ & $1.047(0.273)$ \\
Mental Disorder hospitalization (yes) & $0.436(0.061)$ & $0.515(0.176)$ \\
Physician empathy low (I0-30 points) & & $(<0.001)$ \\
Physician empathy middle (3I-40 points) & & $4.720(0.008)$ \\
Physician empathy high (4I-50 points) & & $18.188(<0.001)$ \\
Constant & $0.255(0.081)$ & $0.021(<0.001)$ \\
$R^{2}$ & 0.160 & 0.375
\end{tabular}

Notes: Model IA: basic model. Model 2A: physician empathy.

Abbreviations: ISS, Injury Severity Score; SEMTO6W, subjective evaluation of medical treatment outcome 6 weeks after discharge. 
Table 7 Results of logistic regression models with the dichotomized variable SEMTOI2M as the dependent variable

\begin{tabular}{|c|c|c|c|}
\hline $\begin{array}{l}\text { Dependent variable: SEMTOI2M } \\
\text { dichotomized }\end{array}$ & $\begin{array}{l}\text { Model I B odds ratios } \\
\text { ( } P \text {-values) } N=136\end{array}$ & $\begin{array}{l}\text { Model } 2 B \text { odds ratios } \\
\text { (P-values) } N=136\end{array}$ & $\begin{array}{l}\text { Model 3B odds } \\
\text { ratios ( } P \text {-values) } \\
\mathrm{N}=136\end{array}$ \\
\hline Age (per year) & $\mathrm{I} .009(0.508)$ & $1.010(0.505)$ & $1.005(0.745)$ \\
\hline Sex (female) & $0.835(0.647)$ & $1.010(0.981)$ & $1.329(0.534)$ \\
\hline High school (yes) & $1.715(0.186)$ & $\mathrm{I} .304(0.540)$ & I.3II (0.556) \\
\hline Partner (yes) & $2.479(0.039)$ & $3.175(0.015)$ & $3.696(0.011)$ \\
\hline Length of stay in hospital (days) & $0.999(0.943)$ & $\mathrm{I} .003(0.87 \mathrm{I})$ & $1.006(0.753)$ \\
\hline ISS (per point on scale) & $1.021(0.611)$ & $1.036(0.419)$ & $\mathrm{I} .048(0.291)$ \\
\hline 6 W SF-36 PSS (per point) & & $\mathrm{I} .087(0.007)$ & $1.088(0.008)$ \\
\hline 6 W SF-36 MSS (per point) & & $1.018(0.261)$ & $1.016(0.327)$ \\
\hline Physician empathy low (10-30 points) & & & $(0.002)$ \\
\hline Physician empathy middle ( $3 \mathrm{I}-40$ points) & & & $0.987(0.982)$ \\
\hline Physician empathy high (4I-50 points) & & & $4.265(0.009)$ \\
\hline Constant & $0.262(0.127)$ & $0.005(0.003)$ & $0.00 I(0.002)$ \\
\hline$R^{2}$ & 0.161 & 0.230 & 0.335 \\
\hline
\end{tabular}

Notes: Model IB: basic model. Model 2B: quality of life. Model 3B: quality of life and physician empathy.

Abbreviations: 6 W SF-36, 6-week 36-Item Short Form Survey Instrument; ISS, Injury Severity Score; MSS, Mental Summary Score; PSS, Physical Summary Score; SEMTO 2 M, subjective evaluation of medical treatment outcome 12 months after discharge.

and having at least one mental disorder at hospitalization were not significant predictors for the dependent variable SEMTO 6 weeks after discharge. "Physician empathy" was added in Model 2A. In this model, living together with a partner led to an about 3.2-fold higher chance to be in the high SEMTO group ( $P=0.010,95 \%$ CI: $1.325-7.612)$. Compared to the lowest empathy group, the group with a rating of 31 to 40 points had a 4.7 -fold increased chance $(P=0.008,95 \%$ CI: $1.509-14.759)$, and the group with a rating of 41 points and above had an 18-fold increased chance $(P<0.001,95 \%$ CI: $5.756-57.470)$ to be in the high SEMTO group 6 weeks after discharge (Nagelkerkes $R^{2}=37.5 \%$ ). Compared to Model $1 \mathrm{~A}$, the logistic regression on SEMTO at 12 months after discharge showed similar results in Model 1B (Table 7): Living together with a partner was significantly correlated with a 2.5 -fold higher chance to be in the high SEMTO group 12 months after discharge ( $P=0.039,95 \%$ CI: 1.048-5.863; Nagelkerke's $\left.R^{2}=16.1 \%\right)$. The SF-36 Mental Summary Score at 6 weeks after discharge was not significantly correlated with the dependent variable (Model 2B; Table 7). Instead, a positive correlation occurred between the SF-36 Physical Summary Score and SEMTO 12 months after discharge $(P=0.007$, 95\% CI: 1.023-1.154), which also remained in Model 3B (Table 7; $P=0.008,95 \%$ CI: 1.022-1.159). A one point rise in the SF-36 Physical Summary Score was associated with an $8.8 \%$ higher probability to be in the high SEMTO group. In Model 3B, the group of patients with physician empathy ratings of 41 points and above had a 4.3 -fold higher chance to be in the high SEMTO group $(P=0.009$,
95\% CI: 1.440-12.629). The middle empathy group did not correlate with the dependent variable. The introduction of "physician empathy" into the logistic regression model led to a more than $10 \%$ increase of the explained variance of SEMTO 12 months after discharge, as Nagelkerke's $R^{2}$ rose from 23.0\% (Model 2B) to 33.5\% (Model 3B). The variable "physician empathy" contributed - with a rise in Nagelkerke's $R^{2}$ from $16.9 \%$ in Model $1 \mathrm{~A}$ to $37.5 \%$ in Model 2A - explained over 20\% of the variance of the SEMTO 6 weeks after discharge. In all of the presented models, "physician empathy" was the strongest predictor for having a SEMTO rating of 3.5 and higher. Age, sex,

Table 8 Comparison of the study population with dropout patients: means ( $t$-test), percentages (chi-square test), and $P$-values

\begin{tabular}{|c|c|c|c|}
\hline & Participants & Dropouts & $P$-value \\
\hline \multicolumn{4}{|l|}{ 6-weeks follow-up } \\
\hline $\mathrm{Age}^{\mathrm{a}}$, years & 46.6 & 39.7 & 0.021 \\
\hline \multicolumn{4}{|l|}{ Sex } \\
\hline Female, n (\%) & $88(46.3)$ & $3(11.1)$ & 0.001 \\
\hline Male, n (\%) & $102(53.7)$ & $24(88.9)$ & \\
\hline ISS ${ }^{a}$, mean & 6.2 & 7.73 & 0.493 \\
\hline Length of stay ${ }^{\mathrm{a}}$ (days), mean & 13.8 & 13.5 & 0.915 \\
\hline \multicolumn{4}{|l|}{ I2-months follow-up } \\
\hline $\mathrm{Age}^{\mathrm{a}}$, years & 47.5 & 40.2 & 0.002 \\
\hline \multicolumn{4}{|l|}{ Sex } \\
\hline Female, n (\%) & $78(47.3)$ & $13(25.0)$ & 0.005 \\
\hline Male, n (\%) & $87(52.7)$ & $39(75.0)$ & \\
\hline ISS , mean & 6.6 & 5.5 & 0.236 \\
\hline Length of stay (days), mean & 13.8 & 13.7 & 0.926 \\
\hline
\end{tabular}

Notes: andependent samples $t$-test. ${ }^{b} \mathrm{Chi}$-square test. Abbreviation: ISS, Injury Severity Score. 
Table 9 Mean differences of SEMTO6W and SEMTOI2M by physician empathy groups

\begin{tabular}{|c|c|c|}
\hline & SEMTO6Wa $(n=183)$ & SEMTOI $2 M^{a}(n=\mid 44)$ \\
\hline & Mean (SD) & Mean (SD) \\
\hline \multicolumn{3}{|l|}{ Physician } \\
\hline \multicolumn{3}{|l|}{ empathy } \\
\hline 10 to 30 points & $2.86(0.57)$ & $2.77(0.82)$ \\
\hline 31 to 40 points & $3.28(0.57)$ & $3.13(0.62)$ \\
\hline 41 to 50 points & $3.63(0.49)$ & $3.55(0.5 \mathrm{I})$ \\
\hline$P$-value ${ }^{\text {b }}$ & $<0.005$ & $<0.05$ \\
\hline
\end{tabular}

Notes: aPossible values between I and 4. 'For ANOVA post-hoc tests: Scheffé, Bonferroni, and Gabriel.

Abbreviations: SD, standard deviation; SEMTO6W, subjective evaluation of medical treatment outcome 6 weeks after discharge; SEMTOI2M, subjective evaluation of medical treatment outcome 12 months after discharge.

high school education, length of stay, and ISS did not show any significant correlation within all models.

\section{Discussion}

The association of 136 patients' subjective evaluations of the medical treatment outcome 12 months after discharge with inpatient physician empathy was investigated, controlling for patient and disease characteristics and health-related quality of life at 6 weeks after discharge. The same analysis was carried out for the 6-week follow-up subjective evaluation of medical treatment outcome, and results were compared. The level of the subjectively evaluated treatment outcome for both follow-up dates is comparable to the results from the pre-phase study group of the previous analysis and those by Janssen et al. ${ }^{22,28}$ Physician empathy ratings during the injured patients' hospitalization were identified as a significant predictor for a higher subjective evaluation of medical treatment outcome 12 months after discharge. Compared to patients who rated the empathy of the surgeons in hospital up to 30 points on the CARE Measure, patients with a rating of 41 points and above had a significantly higher chance of a high subjective evaluation of medical treatment outcome. In comparison with the results of the short-term evaluation 6 weeks after discharge from hospital, the effect size of physician empathy was much smaller 12 months after discharge. Additionally, in the analysis of the long-term subjective treatment outcome, no association was found for patients with middle range empathy ratings 12 months after discharge. Though the effect size of physician empathy was smaller in the long-term, there was still an obvious correlation of physician empathy with the patients' perception of the treatment efficacy, treatment satisfaction, and treatment effect on quality of life. Regarding the lack of correlation between the middle empathic group and subjective treatment outcomes, it seems that a certain empathy level in trauma surgery is needed to produce a change in the patients' outcome. Our results underline that not only short-term, but also higher long-term patient outcomes in trauma surgery, go along with better emotional clinician care in a setting where technical and medical skills seem to dominate the treatment. ${ }^{28}$ As already discussed and concluded within a previous analysis, the level of physician empathy perceived within this sample of trauma patients is increasable, and ideas for a positive development in this surgical specialty were suggested. ${ }^{28}$ The replicability of the results for patients' long-term subjective evaluation of medical treatment outcome underlines these conclusions. The survey of patients' evaluation of the medical treatment outcome after 12 months adds helpful information to the 12-month health-related quality of life data. The SF-36 Summary Scores increased over time and can show the health development of injured patients toward an improvement of physical and mental status. Outcomes research on injured patients has shown that health-related quality of life increases in the long run. . $2,5,6,8,18,52-55$ Compared to the healthy population, the level of our study patients' health-related quality of life 12 months after discharge from the hospital was still low, which is characteristic of accident victims at this date. ${ }^{1,6,8,56}$ Although health-related quality of life, as surveyed with the SF-36, gives fundamental information on patients' physical, pain, or mental status, it does not include a direct link between the received treatment and the patients' perceived benefit of their outcome. This gap might be closed by the additional assessment of subjective treatment outcomes, as assessed with the SEMTO CPQ scale. Compared to the 6-week follow-up, patients rated their subjective treatment outcome lower at the time of 12 months after discharge. The difference is relatively small but still significant. While the health-related quality of life increased from 6 weeks to 12 months after discharge, patients' perception of the treatment benefits seems to be relatively robust over time, with a slight decrease. Goldstein et al assumed that in the long run "selective forgetting" causes differences in perceiving interventions and thus differences in evaluations of patient satisfaction. ${ }^{57}$ Janssen et al found that within the group of patients with negative results for subjective evaluation of treatment outcome, the medium ranking of "time after discharge" was higher than within the group of patients with positive subjective evaluation of treatment outcome, but the difference was not significant. ${ }^{22}$ Ferreira found lower patient satisfaction scores 5 months after discharge compared to 1 month after discharge from the hospital. ${ }^{58}$ Patient satisfaction was shown to be time sensitive, as it depends on the development of outcomes. ${ }^{59,60}$ In the long-term and short-term 
regression analyses, patients living with their partner had higher chances for a high medical treatment outcome. This result confirms the result of the previous analysis, where it was already discussed. ${ }^{28}$ The authors assumed that healthrelated quality of life and patients' evaluation of medical treatment outcome at the 6-week follow-up would reveal a high statistical correlation due to a conceptual overlap. The results of the $t$-test for mean differences did not confirm this assumption to the predicted extent. Though the mean value of the mental summary score within the low short-term subjective treatment outcome group was significantly lower, no difference was found for physical-health-related quality of life. On the other hand, the mean value of the physicalhealth-related quality of life 12 months after discharge was significantly higher in the high long-term subjective treatment outcome group, but no significant difference was found for the mental summary score. In contrast to the 6-week SEMTO outcomes, no SEMTO group differences in frequency distribution were identified for mental disorders assessed at hospitalization in the 12-month follow-up. It is possible that these psychological disorders diagnosed at the time of hospitalization declined to a certain degree 1 year after discharge, whereas other mental problems are persistent or arise later, as the appearance of anxiety and depression showed for our study population 12 months after discharge. ${ }^{8}$ As posttraumatic stress was not assessed at the 12 months follow-up, the validity of our results is limited to anxiety and depression symptoms. Age correlated positively with the short-term medical treatment outcome, which may be explained with a generally higher patient satisfaction in older patients. ${ }^{61-63}$ Other studies showed that age may be associated with worsened outcomes or does not correlate with outcome measures..$^{7,9,52,64}$ In combination with physician empathy, the age effect disappears, which may be assumed to result from higher empathy ratings with advancing age. ${ }^{61-63,65}$ Actually, no bivariate correlation between patient age and empathy rating was found within our study sample. The control variables sex, education, injury severity, and length of stay did not correlate with subjective evaluation of treatment outcome.

\section{Conclusion}

Several limitations of our analyses and results should be considered. First, although longitudinal data are presented, causal inferences cannot be drawn as there might be hidden aspects that lead to correlations. Second, due to a small sample size and the study design, a generalization to other trauma patients should be considered with caution. Future studies should be conducted at diverse study sites. Third, all data were gathered by the same survey method, which might lead to a common method variance. ${ }^{66}$ Possible practical solutions for future studies were already presented. ${ }^{28,67}$ Fourth, dropout patients differed significantly in age and sex. As age was positively correlated to a higher subjective treatment outcome, the effect within this study might be underestimated due to the dropout of younger study patients. Sex did not show any effect in our study. Results regarding the association of surgery patients' sex with outcome evaluation are inconsistent. ${ }^{22,68}$ Fifth, posttraumatic stress was not measured 12 months after discharge. This reduces the significance of the depicted results on mental health outcomes. Finally, most of the variance in the dependent variable subjective evaluation of medical treatment outcome remains still unexplained and seems to hark back to aspects that are not yet identified. To explore those aspects and their controllability, further information has to be gathered by qualitative research and field studies. It is worthwhile to increase short-term and long-term treatment outcomes of patients, for the benefit of patients and society in general. ${ }^{69,70}$ The findings from our 12-month follow-up confirm the results of the previous study. ${ }^{28}$ As these and other study results show, long-term health-related quality of life in patients who suffered an accident may be at a very low level. ${ }^{2,5,6,71}$ Nevertheless the measurement of subjective evaluation of the treatment and physician empathy may provide additional information regarding the options to help by means of emotional care and may serve to detect the limits of technical and medical skills. Additionally, the subjective evaluation of medical treatment outcome may give surgeons a motivating feedback, as the results may still be positive even if injured patients do not fully recover. ${ }^{72}$ In many countries, such as Germany, medical care is performed at very high technical standards and medical skills. But medical care still is a human service - provided by humans. The authors assume the relational aspect is one of the most important key levers to improve treatment outcomes, and the results of our short-term and long-term considerations underline this assumption. Many studies have already shown the importance of the "human factor" in medical treatment. ${ }^{73-78}$ These and the present results might be motivating for trauma surgeons not only to save lives but also to see the seemingly "invisible wounds" that trauma patients bring with them to the hospital that also need curing. ${ }^{73}$ The time has come to transfer these and similar study results into clinical practice. Further research should figure out what helps trauma surgeons or clinicians generally to find the time and place to sympathize with their patients. ${ }^{79-83}$ Health care providers, scientists, politicians, and other stakeholders should put greater efforts 
into implementing psychosocial quality in medical care. A routine measurement of subjective evaluation of medical treatment outcome and physician empathy may give surgeons immediate feedback about their patients' perceptions. If those measurements serve to identify the need for an improvement of empathy, then communication training can offer surgeons a protected area to learn how to deal with patients' concerns and eventually enhance treatment outcomes. ${ }^{84,85}$

\section{Acknowledgments}

The study was funded by the German Research Foundation (DFG, PF 407/2-1). The funding body did not influence any part of the scientific process. We are indebted to DFG und Köln Fortune.

Simone Steinhausen collected and interpreted the data, conducted the analyses, and drafted the manuscript. Holger Pfaff, Oliver Ommen, and Rolf Lefering designed the study and supervised the work together with Edmund Neugebauer. Sonja Thüm and Alexandra Schneider included the patients in the study, and collected and arranged part of the data. SunyaLee Antoine revised the manuscript critically and checked the language. Thorsten Koehler revised the manuscript critically and reviewed the statistical analyses. Simone Steinhausen, Oliver Ommen, and Rolf Lefering had full access to all data in the study and take responsibility for the integrity of the data and the accuracy of the data analysis. Christina Wagner has proofread and revised the manuscript with regard to language. The authors have all read and approved the final version.

\section{Disclosure}

The authors report no conflicts of interest in this work.

\section{References}

1. Soberg HL, Finset A, Bautz-Holter E, Sandvik L, Roise O. Return to work after severe multiple injuries: a multidimensional approach on status 1 and 2 years postinjury. J Trauma. 2007;62(2):471-481.

2. Soberg HL, Roise O, Bautz-Holter E, Finset A. Returning to work after severe multiple injuries: multidimensional functioning and the trajectory from injury to work at 5 years. J Trauma. 2011;71(2):425-434.

3. Berecki-Gisolf J, Collie A, McClure R. Work disability after road traffic injury in a mixed population with and without hospitalisation. Accid Anal Prev. 2013;51:129-134.

4. Anke AG, Stanghelle JK, Finset A, Roaldsen KS, Pillgram-Larsen J, Fugl-Meyer AR. Long-term prevalence of impairments and disabilities after multiple trauma. J Trauma. 1997;42(1):54-61.

5. Hours M, Chossegros L, Charnay P, et al. Outcomes one year after a road accident: Results from the ESPARR cohort. Accid Anal Prev. 2013;50:92-102.

6. Nhac-Vu HT, Hours M, Charnay P, et al. Predicting self-reported recovery one year after major road traffic accident trauma. J Rehabil Med. 2011;43(9):776-782.

7. Holbrook TL, Hoyt DB. The impact of major trauma: quality-of-life outcomes are worse in women than in men, independent of mechanism and injury severity. J Trauma. 2004;56(2):284-290.
8. Soberg HL, Bautz-Holter E, Roise O, Finset A. Mental health and posttraumatic stress symptoms 2 years after severe multiple trauma: self-reported disability and psychosocial functioning. Arch Phys Med Rehabil. 2010;91(3):481-488.

9. Vles WJ, Steyerberg EW, Essink-Bot ML, van Beeck EF, Meeuwis JD, Leenen LP. Prevalence and determinants of disabilities and return to work after major trauma. J Trauma. 2005;58(1):126-135.

10. Pirente N, Blum C, Wortberg S, et al. Quality of life after multiple trauma: the effect of early onset psychotherapy on quality of life in trauma patients. Langenbecks Arch Surg. 2007;392(6):739-745.

11. Kehlet H. [Principles of fast track surgery. Multimodal perioperative therapy programme]. Chirurg. 2009;80(8):687-689. German.

12. Kosar S, Seelen HA, Hemmen B, Evers SM, Brink PR. Cost-effectiveness of an integrated 'fast track' rehabilitation service for multi-trauma patients involving dedicated early rehabilitation intervention programs: design of a prospective, multi-centre, non-randomised clinical trial. J Trauma Manag Outcomes. 2009;3:1.

13. Petersen C, Ullrich A, Wahls F, et al. Psychosocial impairments and resources of multiple injured patients. Phys Med Rehab Kuror. 2008; 18(6):313-317.

14. Bouillon B, Kreder HJ, Eypasch E, et al; MI Consensus Group. Quality of life in patients with multiple injuries - basic issues, assessment, and recommendations. Restor Neurol Neurosci. 2002;20(3-4): $125-134$.

15. Neugebauer E, Bouillon B, Bullinger M, Wood-Dauphinée S. Quality of life after multiple trauma - summary and recommendations of the consensus conference. Restor Neurol Neurosci. 2002;20(3-4): 161-167.

16. Koller M, Neugebauer EA, Augustin M, et al. [Assessment of quality of life in health services research - conceptual, methodological and structural prerequisites]. Gesundheitswesen. 2009;71(12):864-872. German.

17. Pfaff H, Glaeske G, Neugebauer EA, Schrappe M; Zentrum für Versorgungsforschung Köln (ZVFK) der Uniklinik Köln; Zentrum für Sozialpolitik (ZeS), Universität Bremen; IFOM-Institut für Forschung in der Operativen Medizin der Privaten Universität Witten/Herdecke; Klinikum der Johann Wolfgang Goethe-Universität Frankfurt am Main. [Memorandum III: "Methods for Health Services Research" (Part 1)]. Gesundheitswesen. 2009;71(8-9):505-510. German.

18. Soberg HL, Bautz-Holter E, Roise O, Finset A. Long-term multidimensional functional consequences of severe multiple injuries two years after trauma: a prospective longitudinal cohort study. J Trauma. 2007;62(2):461-470.

19. Swiontkowski MF. Outcomes measurement in orthopaedic trauma surgery. Injury. 1995;26(10):653-657.

20. Gosling CM, Gabbe BJ, Williamson OD, Sutherland AM, Cameron PA. Validity of outcome measures used to assess one and six month outcomes in orthopaedic trauma patients. Injury. 2011;42(12): 1443-1448.

21. Shearer D, Morshed S. Common generic measures of health related quality of life in injured patients. Injury. 2011;42(3):241-247.

22. Janssen C, Ommen O, Ruppert G, Pfaff H. Patient- and hospital-related determinants on subjective evaluation of medical treatment outcome of severely injured patients. Int J Public Health. 2008;16(1):53-60.

23. Revicki DA. Patient assessment of treatment satisfaction: methods and practical issues. Gut. 2004;53(Suppl 4):iv40-iv44.

24. Kravitz RL. Patients' expectations for medical care: an expanded formulation based on review of the literature. Med Care Res Rev. 1996; 53(1):3-27.

25. Sørlie T, Sexton HC, Busund R, Sørlie D. Predictors of satisfaction with surgical treatment. Int J Qual Health Care. 2000;12(1):31-40.

26. Pfaff H, Freise DC, Mager G, Schrappe M. Der Kölner Patientenfragebogen (KPF): Entwicklung und Validierung eines Fragebogens zur Erfassung der Einbindung des Patienten als Kotherapeuten [The Cologne Patient Questionnare (CPQ): Development and validation of a questionnaire to measure patient involvement as co-therapist]. Sankt Augustin: Asgard-Verlag; 2003. German. 
27. Mercer SW, Neumann M, Wirtz M, Fitzpatrick B, Vojt G. General practitioner empathy, patient enablement, and patient-reported outcomes in primary care in an area of high socio-economic deprivation in Scotland - a pilot prospective study using structural equation modeling. Patient Educ Couns. 2008;73(2):240-245.

28. Steinhausen $\mathrm{S}$, Ommen $\mathrm{O}$, Thüm $\mathrm{S}$, et al. Physician empathy and subjective evaluation of medical treatment outcome in trauma surgery patients. Patient Educ Couns. 2014;95(1):53-60.

29. Hax P-M, Hax-Schopenhorst T. Kommunikation mit Patienten in der Chirurgie: Praxisempfehlungen für Ärzte aller operativen Fächer [Communication with patients in surgery: praxical recommendations for physicians of all surgical specialties]. Stuttgart: Kohlhammer; 2012. German.

30. Macnaughton J. The dangerous practice of empathy. Lancet. 2009; 373(9679):1940-1941.

31. Kravitz RL, Callahan EJ, Paterniti D, Antonius D, Dunham M, Lewis CE. Prevalence and sources of patients' unmet expectations for care. Ann Intern Med. 1996;125(9):730-737.

32. Mercer SW, Reynolds WJ. Empathy and quality of care. Br J Gen Pract. 2002;52 Suppl:S9-S12.

33. Strietzel FP, Reichart PA. Oral rehabilitation using Camlog screw-cylinder implants with a particle-blasted and acid-etched microstructured surface. Results from a prospective study with special consideration of short implants. Clin Oral Implants Res. 2007;18(5):591-600.

34. Ahrens W, Bellach B-M, Jöckel K-H. Messung soziodemographischer Merkmale in der Epidemiologie [Measurement of sociodemographic characteristics in epidemiology]. München: MMV, Medizin-Verlag; 1998. German.

35. Dillman DA. Mail and telephone surveys: the total design method. New York: Wiley; 1978.

36. Buecken R, Galushko M, Golla H, et al. Patients feeling severely affected by multiple sclerosis: How do patients want to communicate about end-of-life issues? Patient Educ Couns. 2012;88(2): 318-324.

37. Kowalski C, Nitzsche A, Scheibler F, Steffen P, Albert US, Pfaff H. Breast cancer patients' trust in physicians: the impact of patients' perception of physicians' communication behaviors and hospital organizational climate. Patient Educ Couns. 2009;77(3):344-348.

38. Ommen O, Thuem S, Pfaff H, Janssen C. The relationship between social support, shared decision-making and patient's trust in doctors: a cross-sectional survey of 2,197 inpatients using the Cologne Patient Questionnaire. Int J Public Health. 2011;56(3):319-327.

39. Ommen O, Wirtz M, Janssen C, Neumann M, Ernstmann N, Pfaff H. Validation of a theory-based instrument measuring patient-reported psychosocial care by physicians using a multiple indicators and multiple causes model. Patient Educ Couns. 2010;80(1):100-106.

40. Neumann M, Wirtz M, Bollschweiler E, Warm M, Wolf J, Pfaff H. [Psychometric evaluation of the German version of the "Consultation and Relational Empathy" (CARE) measure at the example of cancer patients]. Psychother Psychosom Med Psychol. 2008;58(1):5-15. German.

41. Mercer SW, Maxwell M, Heaney D, Watt GC. The consultation and relational empathy (CARE) measure: development and preliminary validation and reliability of an empathy-based consultation process measure. Fam Pract. 2004;21(6):699-705.

42. The CARE Measure [Internet]. Mercer SW; 2004. Available from: http:// www.gla.ac.uk/media/media_65352_en.pdf. Accessed Nov 19, 2013.

43. Mercer SW, Jani BD, Maxwell M, Wong SY, Watt GC. Patient enablement requires physician empathy: a cross-sectional study of general practice consultations in areas of high and low socioeconomic deprivation in Scotland. BMC Fam Pract. 2012;13:6.

44. Mercer SW, McConnachie A, Maxwell M, Heaney D, Watt GC. Relevance and practical use of the Consultation and Relational Empathy (CARE) Measure in general practice. Fam Pract. 2005; 22(3):328-334.

45. Neumann M, Wirtz M, Bollschweiler E, et al. Determinants and patient-reported long-term outcomes of physician empathy in oncology: a structural equation modelling approach. Patient Educ Couns. 2007;69(1-3):63-75.
46. Bullinger M, Kirchberger I. SF-36: Fragebogen zum Gesundheitszustand; Handanweisung [Questionnaire on state of health Short-Form 36; Manual]. Z Med Psychol. 1998;7(4):190-191. German.

47. Ommen O, Wirtz M, Janssen C, et al. Psychometric evaluation of an instrument to assess patient-reported 'psychosocial care by physicians': a structural equation modeling approach. Int $J$ Qual Health Care. 2009;21(3): 190-197.

48. Copes WS, Champion HR, Sacco WJ, et al. Progress in characterizing anatomic injury. J Trauma. 1990;30(10):1200-1207.

49. Herrmann-Lingen C, Buss U, Snaith RP. HADS-D: Hospital anxiety and depression scale; ein Fragebogen zur Erfassung von Angst und Depressivität in der somatischen Medizin; Testdokumentation und Handanweisung. 2nd ed. Bern: Huber; 2005. German.

50. Snaith RP. The hospital anxiety and depression scale. Br J Gen Pract. 1990;40(336):305.

51. Maercker A, Schutzwohl M. Erfassung von psychischen Belastungssfolgen: Die Impact of Event Skala - revidierte Version. [Assessment of post-traumatic stress reactions: The impact of Event Scale - Revised]. Diagnostica. 1998;44(3):130-141. German.

52. Holtslag HR, van Beeck EF, Lindeman E, Leenen LP. Determinants of long-term functional consequences after major trauma. $J$ Trauma. 2007;62(4):919-927.

53. Holbrook TL, Anderson JP, Sieber WJ, Browner D, Hoyt DB. Outcome after major trauma: discharge and 6-month follow-up results from the Trauma Recovery Project. J Trauma. 1998;45(2):315-323; discussion 323-314.

54. Holbrook TL, Anderson JP, Sieber WJ, Browner D, Hoyt DB. Outcome after major trauma: 12-month and 18-month follow-up results from the Trauma Recovery Project. J Trauma. 1999;46(5):765-771; discussion 771-773.

55. Khati I, Hours M, Charnay P, et al. Quality of life one year after a road accident: results from the adult ESPARR cohort. J Trauma Acute Care Surg. 2013;74(1):301-311.

56. Kurth BM, Ellert U. The SF-36 questionnaire and its usefulness in population studies: results of the German Health Interview and Examination Survey 1998. Soz Praventivmed. 2002;47(4):266-277.

57. Goldstein MS, Elliott SD, Guccione AA. The development of an instrument to measure satisfaction with physical therapy. Phys Ther. 2000;80(9):853-863.

58. Ferreira PL. Stability of Patient Perception of Quality of Hospital Care Over Time. In: Lun KC, Degoulet P, Piemme TE, Rienhoff O, editors. MEDINFO 92. Proceedings of the Seventh World Congress on: Medical Informatics, Geneva Palexpo, Switzerland, 6-10; September 1992. Amsterdam: North Holland; 1992:1535-1539.

59. Trout A, Magnusson AR, Hedges JR. Patient satisfaction investigations and the emergency department: what does the literature say? Acad Emerg Med. 2000;7(6):695-709.

60. Powers TL, Bendall D. The influence of time on changes in health status and patient satisfaction. Health Care Manage Rev. 2004; 29(3):240-248

61. Jackson JL, Chamberlin J, Kroenke K. Predictors of patient satisfaction. Soc Sci Med. 2001;52(4):609-620.

62. Nguyen Thi PL, Briançon S, Empereur F, Guillemin F. Factors determining inpatient satisfaction with care. Soc Sci Med. 2002; 54(4):493-504.

63. Hekkert KD, Cihangir S, Kleefstra SM, van den Berg B, Kool RB. Patient satisfaction revisited: a multilevel approach. Soc Sci Med. 2009;69(1):68-75.

64. Michaels AJ, Michaels CE, Smith JS, Moon CH, Peterson C, Long WB. Outcome from injury: general health, work status, and satisfaction 12 months after trauma. $J$ Trauma. 2000;48(5):841-848; discussion $848-850$.

65. Duberstein P, Meldrum S, Fiscella K, Shields CG, Epstein RM. Influences on patients' ratings of physicians: Physicians demographics and personality. Patient Educ Couns. 2007;65(2):270-274.

66. Podsakoff PM, MacKenzie SB, Lee JY, Podsakoff NP. Common method biases in behavioral research: a critical review of the literature and recommended remedies. J Appl Psychol. 2003;88(5):879-903. 
67. Podsakoff PM, MacKenzie SB, Podsakoff NP. Sources of method bias in social science research and recommendations on how to control it. Annu Rev Psychol. 2012;63:539-569.

68. Hudak PL, Hogg-Johnson S, Bombardier C, McKeever PD, Wright JG. Testing a new theory of patient satisfaction with treatment outcome. Med Care. 2004;42(8):726-739.

69. Swiontkowski MF, Chapman JR. Cost and effectiveness issues in care of injured patients. Clin Orthop Relat Res. 1995;(318):17-24.

70. United Nations General Assembly. Global road safety crisis. Report of the Secretary-General. United Nations; 2003:1-11. Available from http://www.unece.org/fileadmin/DAM/trans/roadsafe/docs/ SG_report_e.pdf. Accessed August 12, 2014.

71. Leitgeb J, Mauritz W, Brazinova A, et al. Glasgow Coma Scale score at intensive care unit discharge predicts the 1-year outcome of patients with severe traumatic brain injury. Eur J Trauma Emerg Surg. 2013;39(3):285-292.

72. Harris IA, Dao AT, Young JM, Solomon MJ, Jalaludin BB. Predictors of patient and surgeon satisfaction after orthopaedic trauma. Injury. 2009;40(4):377-384.

73. Burcher P. Emotional intelligence and empathy: its relevance in the clinical encounter. Patient Intelligence. 2011;3:23-28.

74. Kaptchuk TJ, Kelley JM, Conboy LA, et al. Components of placebo effect: randomised controlled trial in patients with irritable bowel syndrome. BMJ. 2008;336(7651):999-1003.

75. Di Blasi Z, Harkness E, Ernst E, Georgiou A, Kleijnen J. Influence of context effects on health outcomes: a systematic review. Lancet. 2001;357(9258):757-762.
76. Brody H. Medicine's continuing quest for an excuse to avoid relationships with patients. Am J Bioeth. 2009;9(12):13-15.

77. Merrill JM, Laux L, Thornby JI. Troublesome aspects of the patientphysician relationship: a study of human factors. South Med J. 1987; 80(10):1211-1215.

78. Dunn SM. Barriers and challenges in training health care providers for patient education. Patient Educ Couns. 1995;26(1-3):131-138.

79. Halpern J. Empathy and patient-physician conflicts. J Gen Intern Med. 2007;22(5):696-700.

80. Halpern J. What is clinical empathy? J Gen Intern Med. 2003;18(8) 670-674.

81. Halpern J. Practicing medicine in the real world: challenges to empathy and respect for patients. J Clin Ethics. 2003;14(4):298-307.

82. Gleichgerrcht E, Decety J. Empathy in clinical practice: how individual dispositions, gender, and experience moderate empathic concern, burnout, and emotional distress in physicians. PLoS One. 2013;8(4):e61526.

83. Neumann M, Scheffer C, Längler A, et al. [Relevance and barriers of physician empathy in daily practice - current state of research and qualitative survey of physicians]. Rehabilitation (Stuttg). 2010;49(5): 326-337. German.

84. Bonvicini KA, Perlin MJ, Bylund CL, Carroll G, Rouse RA, Goldstein MG. Impact of communication training on physician expression of empathy in patient encounters. Patient Educ Couns. 2009;75(1):3-10.

85. Stewart MA. Effective physician-patient communication and health outcomes: a review. CMAJ. 1995;152(9):1423-1433.
Patient Preference and Adherence

\section{Publish your work in this journal}

Patient Preference and Adherence is an international, peer-reviewed, open access journal that focuses on the growing importance of patient preference and adherence throughout the therapeutic continuum. Patient satisfaction, acceptability, quality of life, compliance, persistence and their role in developing new therapeutic modalities and compounds to optimize

\section{Dovepress}

clinical outcomes for existing disease states are major areas of interest for the journal. This journal has been accepted for indexing on PubMed Central. The manuscript management system is completely online and includes a very quick and fair peer-review system, which is all easy to use. Visit http://www. dovepress.com/testimonials.php to read real quotes from published authors. 